Research Article

\title{
Financial Imbalance Risk and Its Control Strategy of China's Pension Insurance Contribution Rate Reduction
}

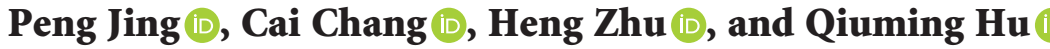 \\ School of Insurance, Southwestern University of Finance and Economics, Chengdu 611130, China \\ Correspondence should be addressed to Qiuming Hu; hqiuming@263.net
}

Received 25 January 2021; Revised 15 February 2021; Accepted 20 February 2021; Published 28 February 2021

Academic Editor: Rongwei Guo

Copyright (C) 2021 Peng Jing et al. This is an open access article distributed under the Creative Commons Attribution License, which permits unrestricted use, distribution, and reproduction in any medium, provided the original work is properly cited.

\begin{abstract}
Within the context of China's Urban Employees' Basic Pension Insurance (UEBPI), this paper constructs an actuarial model to analyze the financial imbalance risk of contribution rate reduction and to investigate the possibility of further reducing the contribution rate. It is found that the UEBPI fund would show financial imbalance risk in 2024 if the contribution rate is $16 \%$, and no control strategy is introduced. In the case of single strategy (the collection system reform, delay of retirement age, or the introduction of external finance), the financial sustainability of the UEBPI fund could be improved to some extent, whereas the financial imbalance risk remains huge. In the case of a package of control strategies being implemented, the UEBPI fund could be able to continue its operation until 2060, and the contribution rate can be further reduced by $0-4$ percentage. Therefore, the implementation of a package of control strategies presents a prerequisite for controlling the financial imbalance risk and further reducing the contribution rate.
\end{abstract}

\section{Introduction}

The contribution rate of China's social insurance is among the highest in the world, particularly the Urban Employees' Basic Pension Insurance (UEBPI). According to "Social Security Programs Throughout the World: Africa, 2015" released by the U.S. Social Security Administration (https:// catalog.data.gov/dataset/social-security-programs-througho ut-the-world-africa-2015), the contribution rate of China's social insurance and pension insurance ranked $16^{\text {th }}$ and $11^{\text {th }}$ among 175 countries or regions, respectively. Several reasons contribute to this high contribution rate, including the high transition cost, the low dependency ratio, the imperfect contribution incentive mechanism, and the improper management of the fund.

At present, China's economy has entered a new stage characterized by the transformation from rapid growth to high-quality development. According to current policies, the employers contribute $30 \%$ of employees' wages to social insurance, which brings a negative impact to their business operations. To lighten the contribution burden, the Chinese government has reduced the contribution rate for several times since 2015. However, those reductions are mainly for employment injury insurance and unemployment insurance. For the pension insurance with the heaviest contribution burden among five social insurances, the contribution rate is reduced by only one percentage. Due to the fact that the reduction is relatively low, more and more employers call for further reduction. In view of this, the Chinese government reduced the UEBPI contribution rate for employers from $19 \%$ to $16 \%$ in May 2019, emphasizing that the reduction is a long-term institutional arrangement and should adapt to the new normal economic development.

The policy objective of lowering the UEBPI contribution rate is to lighten the burdens on employers, while it also results in the reduction of the pension fund's income. Although the accumulated surplus of China's UEBPI fund has reached more than 5 trillion RMB in 2019, which could support the contribution rate reduction in the short term, the financial sustainability of the fund would be threatened in the long run. It can be seen from Figure 1 that the income from the collection was lower than the total expenditure since 2014, and the gap between these two even reached 662.80 billion RMB in 2019. In addition, according to the 


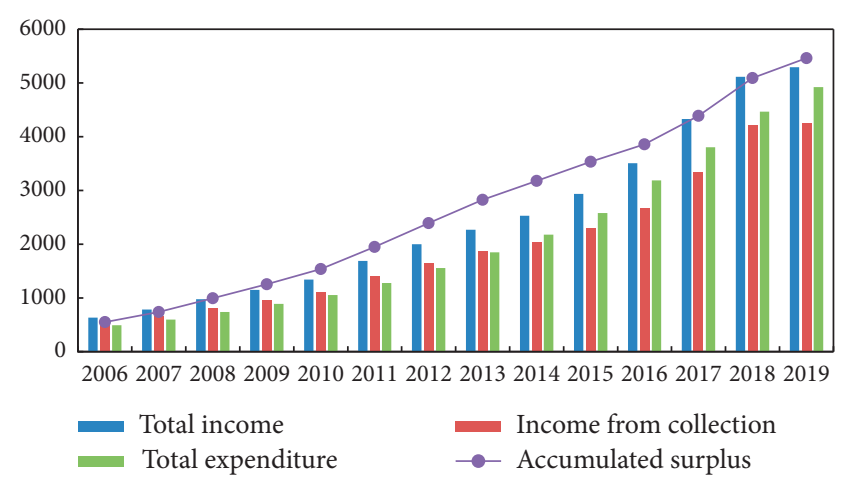

FIGURE 1: Financial balance of the UEBPI fund in 2006-2019 (unit: billion RMB; source: Statistical Bulletin on the Development of Human Resources and Social Security, http://www.mohrss.gov.cn/ $\mathrm{gkml} / \mathrm{ghtj} / \mathrm{tj} / \mathrm{ndtj} /)$.

data of Figure 1, we can calculate that the annual growth rate of total expenditure and total income of the UEBPI fund are $19.47 \%$ and $17.93 \%$, indicating that the fund may have hidden the financial imbalance risk. Previous studies generally concluded that the current arrangement of the UEBPI fund was not sustainable in the long term with the rapid growth of population aging (Liu et al. [1]; Luo et al. [2]), suggesting that the contribution rate reduction will enhance the financial imbalance risk. To achieve the goal of reducing the contribution rate without cutting the pension benefit, the following questions must be answered first, i.e., how much financial imbalance risk exists in the UEBPI fund, and how to mitigate the risk by settling control strategies?

In recent years, the Chinese government has carried out a series of reforms to finance the UEBPI fund, including implementing the two-child policy, encouraging marketoriented investment, and establishing the pension benefit adjustment mechanism. Though these reforms could enhance the financial sustainability, it is unlikely to completely settle the problem of inadequate solvency of pension funds (Xie et al. [3]; Zeng and Yu [4]). Meanwhile, the Chinese government also considers extending the mandatory retirement age and implementing the collection system reform. On the premise of the sustainable operation of the UEBPI fund, is it possible to further reduce the contribution rate in the process of pension system reforms? The answers to the question can provide a quantitative basis for the government to further reduce the UEBPI contribution rate.

The remaining part of this paper is organized as follows. Section 2 reviews the literature. Section 3 constructs an actuarial model to analyze the financial imbalance risk and calculates the contribution rate under actuarial equivalence. Section 4 describes the parameters and assumptions. Section 5 presents the prediction results in several scenarios. Section 6 reports the results of sensitivity analysis. Section 7 concludes the paper.

\section{Literature Review}

In the 1990s, the concept of sustainable development was introduced into the reform of the pension system. Many countries set their ultimate goal of the pension system reform to achieve sustainable development (World Bank [5]). Holzmann and Hinz [6] emphasized that sustainability referred specifically to financial sustainability. In most countries, pension system is confronted with great challenges due to population aging. Therefore, considerable literature is prepared to assess the financial sustainability of pension funds (Blake and Mayhew [7]; Rauh and Novymarx [8]; Billig and Ménard [9]; Metzger [10]). Bongaarts [11] found that the pension fund in most OECD countries would not be sufficient with an aging population because of the Pay-As-You-Go (PAYG) system. Sin [12] found that China's UEBPI fund would have an annual deficit after 2030 and the amount of the accumulated deficit would increase on yearly basis. In this case, to maintain the balance between the fund's income and expenditure, the contribution rate should increase to $37 \%$. To enhance the financial sustainability and alleviate the financial imbalance risk of the pension system, multiple studies have proposed many optimization strategies, such as postponing the mandatory retirement age, lowering the growth rate of pension benefits, relaxing the childbearing policy, and increasing the return on investment of the fund (Belolipetskii and Lepskaya [13]; Heeringa and Bovenberg [14]; Liu and Sun [15]).

In general, existing literature on the pension insurance contribution rate mainly focuses on three aspects. First, from the perspective of fund balance, some literature constructed an actuarial model to predict the financial status and the feasible extent of contribution rate reduction. Second, from the perspective of cost-benefit comparison, some literature empirically analyzed the impact of the contribution rate on employers' behavior. Third, from the perspective of general equilibrium, some literature established an overlapping generation model to estimate the impact of the contribution rate on several essential economic outcomes.

Pension insurance contributions present the main income source of the pension fund; therefore, lowering the contribution rate will inevitably reduce the fund's income and further bring negative impact on the sustainability of the fund. Whiteford and Whitehouse [16] suggested that the premise for the reduction of the contribution rate was to consolidate the contribution base. Lin [17] found that a contribution rate of $16.47 \%$ was required to achieve the vertical financial balance of China's UEBPI fund from 2008 to 2050. Jing and $\mathrm{Hu}$ [18] pointed out that the contribution rate could be kept within $14.64 \%-16.14 \%$ if a combination of policy reforms was performed. Zeng et al. [19] found that the two-child policy could decrease the contribution rate in the short term, while postponing the retirement age could result in a reduction in the rate by $0.30-0.43$ percentage every two years before 2050. Guo and Zhang [20] believed that there was little room for further reduction of the contribution rate in the short term. To obtain a reduction of the rate in the long run, they advised implementing the collection system reform. Zeng et al. [21] found that the contribution rate could be reduced by $0.57-1.50$ percentage between 2020 and 2030 provided that the tax authorities collected pension insurance contributions.

Pension insurance contribution presents a chief component of enterprises' operating costs. The reduction of the 
contribution rate may result in a decrease of the enterprises' labor costs and an increase in cash flow, thus changing their business behaviors. According to Kugler and Kugler [22], enterprises' employment behavior is associated with the cost and benefit of the pension contribution. Their study showed that an increase in the contribution rate may lead to the reduction of formal employment. Iturbe-Ormaetxe [23] reached a similar conclusion. Ma et al. [24] found that the increase of one percent of the pension insurance contribution rate would reduce employment by $0.8 \%$. Chaudhry et al. [25] and Saez et al. [26] found that increasing the contribution rate would reduce the cash flow and squeeze the $R \& D$ expenditures, which is unfavorable for the improvement of production efficiency. Based on the data of Chinese industrial enterprises, Tang and Feng [27] found that the increase of the contribution rate would increase the capital-labor ratio.

Pension insurance contributions profoundly affect personal interests. The changes in the contribution rate may lead to the adjustments of individuals' decision-making behavior, thereby affecting the economic growth through labor supplies and the accumulation of physical and human capital. Ehrlich and Kim [28] found that a higher contribution rate encouraged a lower fertility rate and leaded to a decrease in private savings. Yew and Zhang [29] showed that when parents' preference for their children's utility was greater than that for the number of children, pension insurance would improve social welfare by reducing the fertility rate and increasing human capital. Fanti and Gori [30] illustrated that a lower contribution rate would accumulate physical capital and increase the economic growth rate. Peng et al. [31] showed there was an optimal combinatorial relationship between the pension insurance contribution rate and the tax rate on public education. By increasing public investment in education, it is possible to maintain the pension replacement rate and economic growth rate, while reducing the contribution rate in the meantime.

In summary, existing literature has deeply analyzed the pension insurance contribution rate from different perspectives. However, there is still room for improvement. Firstly, most of the existing studies only focus on one particular pension system reform, and few pieces of literature investigate the impact of multiple reforms on the financial sustainability of pension funds. Secondly, the actuarial model adopted in most studies fails to classify the pension participants, and their assumptions on parameters make no difference between regulation and practice into account. Accordingly, we aim to construct an actuarial model with reasonable parameter assumptions to predict the financial sustainability of China's UEBPI fund in several scenarios. Based on the calculated contribution rate under actuarial equivalence, we also attempt to investigate whether the contribution rate could be further reduced.

\section{Methodology}

3.1. Actuarial Model. In 1997, after the State Council proposed the issue "Decision on Establishing a Unified Basic Pension System for Enterprise Employees," the Chinese government established a public pension program with a social pooling account and an individual account. In 2005, the State Council issued "Decision on Improving the Enterprise Employees' Basic Pension System," which changed the method to calculate pension benefits. According to the time when employees entered the labor market and employees worked until retiring and the implementation of the above two documents, we classify pension participants into four categories, including "old people," "older middle-aged people," "younger middle-aged people," and "young people". The "old people" refers to those who had retired before 1998. The "older middle-aged people" refers to those who started work before 1998 and retired before 2006. The "younger middle-aged people" refers to those who started work before 1998 and retired or will retire after 2006. The "young people" refers to those who started work after 1998. Besides, the current statutory retirement age in China is 60 for males, 55 for female carders, and 50 for female workers, indicating that we should consider the differences in employees' gender and occupation. The purpose of classifying pension participants is to predict the income and expenditure of pension funds more accurately. Finally, we decide to construct the actuarial model combined with the stabilization of chaotic systems and control theory (Yi et al. [32]; Liu et al. [33]).

The pension fund's income (referred to income from the collection) is the multiplication of the number of contributors, contribution base, collection rate, and contribution rate. Thus, the $t$-year pension fund's income, $I_{t}$, is given by

$$
I_{t}=\sum_{i=1}^{4} \sum_{j=1}^{3} \sum_{x=a^{j}}^{b^{j}-1} N_{t, x}^{i, j} \times w_{t} \times \rho_{t} \times(\theta+\sigma)=\sum_{i=1}^{4} \sum_{j=1}^{3} \sum_{x=a^{j}}^{b^{j}-1} N_{t, x}^{i, j} \times\left[w_{t_{0}-1} \times \prod_{s=t_{0}}^{t}\left(1+k_{s}\right)\right] \times \rho_{t} \times(\theta+\sigma) .
$$

In equation (1), $i=1-4$ refers to "old people," "older middle-aged people," "younger middle-aged people," and "young people," respectively. $J=1-3$ refers to male, female carder, and female worker, respectively. $a^{j}$ is the initial contributory age, $b^{j}$ is the retirement age, and $N_{t, x}^{i, j}$ is the number of contributors aged $x$ at year $t$ who belong to the $i$ th and $j$ th group. $w_{t}$ represents the contribution base, $k_{t}$ represents the growth rate of contribution base, $\rho_{t}$ represents the collection rate. $\theta$ and $\sigma$ are the contribution rates of employers and employees, respectively, $t_{0}$ refers to the year in which the actuarial analysis begins. Note that, the above equation is a general form. Under the current retirement age in China, except for the "old people," "older middle-aged people," and part of the "younger middle-aged people," the 
remaining "younger middle-aged people" and all of the "young people" still need to pay for it in 2020. After 2037, only the "young people" need to pay for the contributions.

The pension fund's expenditure consists of basic pension benefits, transitional pension benefits, and individual account pension benefits. According to the regulation of UEBPI, the "old people" can only receive basic pension benefits, the "older middle-aged people" and "younger middle-aged people" can receive three kinds of pension benefits, the "young people" can receive basic pension benefits and individual account pension benefits.

The expenditure of basic pension benefits equals the multiplication of the number of retired members, payment base, payment ratio, and adjustment factor. Thus, the expenditure of basic pension benefits, $E_{t, A}$, is given by

$$
E_{t, A}=\sum_{i=1}^{4} \sum_{j=1}^{3} \sum_{x=b^{j}}^{c^{j}} N_{t, x}^{i, j} \times A_{t, x}^{i, j} \times m_{t, x}^{i, j} \times \prod_{s=t-x+b^{j}}^{t}\left(1+g_{s}\right) .
$$

In equation (2), $c^{j}$ refers to the maximum age of survival, $A_{t, x}^{i, j}$ refers to the payment base of basic pension benefits for members aged $x$ at year $t$ who belong to the $i$ th and $j$ th group, $m_{t, x}^{i, j}$ is the corresponding payment ratio, and $g_{t}$ is the growth rate of basic pension benefits. According to the pension benefits adjustment in practice, we assume that the growth rates of basic pension benefits, transitional pension benefits, and individual account pension benefits are the same.

The expenditure of transitional pension benefits equals the multiplication of the number of retired "older middleaged people" and "younger middle-aged people", payment base, payment ratio, admitted number of years of contributory service, and adjustment factor. Thus, the expenditure of transitional pension benefits, $E_{t, B}$, is given by

$$
E_{t, B}=\sum_{i=2}^{3} \sum_{j=1}^{3} \sum_{x=b^{j}}^{c^{j}} N_{t, x}^{i, j} \times B_{t, x}^{i, j} \times n_{t, x}^{i, j} \times T I_{t, x}^{i, j} \times \prod_{s=t-x+b^{j}}^{t}\left(1+g_{s}\right) .
$$

In equation (3), $B_{t, x}^{i, j}$ refers to the payment base of transitional pension benefits for members aged $x$ at year $t$ who belong to the $i$ th and $j$ th group, $n_{t, x}^{i, j}$ is the corresponding payment ratio, and $T I_{t, x}^{i, j}$ is the admitted number of years of contributory service before the establishment of the individual account, $T I_{t, x}^{i, j}=1998-\left(t-x+a^{j}\right)$.

The expenditure of individual account pension benefits depends on the number of retired "older middle-aged people," "younger middle-aged people," and "young people," their accumulated balance of the individual account, and adjustment factor. Thus, the expenditure of individual account pension benefits, $E_{t, C}$, is given by

$$
E_{t, C}=\sum_{i=2}^{4} \sum_{j=1}^{3} \sum_{x=b^{j}}^{c^{j}} N_{t, x}^{i, j} \times \frac{\sum_{s=a^{j}}^{b^{j}-1} w_{s} \times \sigma_{t} \times\left(1+i_{s}\right)^{b^{j}-s-1}}{v_{t}^{i, j}} \times 12 \times \prod_{s=t-x+b^{j}}^{t}\left(1+g_{s}\right) .
$$

In equation (4), $i_{t}$ refers to the nominal interest rate of individual account at year $t, v_{t}^{i, j}$ is the number of expected months issuing individual account pension benefits for members who belong to the $i$ th and jth groups at year $t$.

The current surplus of the pension fund equals the income minus the expenditure in the current year. The accumulated surplus of the pension fund equals the sum of last year's accumulated surplus, accrued interest, and the current surplus. At year $t$, the current surplus $C S_{t}$ and the accumulated surplus $A S_{t}$ are as follows:

$$
\begin{aligned}
& C S_{t}=I_{t}-E_{t}=I_{t}-\left(E_{t, A}+E_{t, B}+E_{t, C}\right), \\
& A S_{t}=A B_{t-1} \times\left(1+r_{t}\right)+C S_{t},
\end{aligned}
$$

where $r_{t}$ is the return on investment of the pension fund at year $t$. According to the amount of accumulated surplus, $r_{t}$ takes different values. When the accumulated surplus is positive, $r_{t}$ is the actual rate of return on investment. When the accumulated surplus is negative, $r_{t}=0$. By judging the symbol of accumulated surplus, we can evaluate the financial imbalance risk of pension funds. If $A S_{t-1}>0$ and $A S_{t}<0$, the fund will show financial imbalance risk at year $t$.

3.2. Contribution Rate under Actuarial Equivalence Principle. Although China adopts an integrated account that combines a social pooling account and an individual account, a PAYG system is executed in practice. Due to the high transition cost, the Chinese government has to use part of individual account funds to fill the gap in the pooling account, which directly induces the problem of "empty account". Under the PAYG system, the government decides the annual fund's income based on its expenditure and then determines the contribution rate according to the number of contributors and the contribution base. However, it is inadvisable to change the contribution rate frequently because of the menu cost. Therefore, the pension fund should satisfy the vertical financial balance, and the vertical financial balance means that accumulated income equals accumulated expenditure during a certain period, which is given by

$$
\sum_{t=t_{0}}^{t_{T}}\left[I_{t} \times \prod_{s=t}^{t_{T}}\left(1+r_{s}\right)\right]+A S_{t_{0}-1} \times \prod_{t=t_{0}}^{t_{T}}\left(1+r_{t}\right)=\sum_{t=t_{0}}^{t_{T}}\left[E_{t} \times \prod_{s=t_{0}}^{t_{T}}\left(1+r_{s}\right)\right]
$$


where $t_{T}$ is the year of termination of actuarial analysis. Substituting equation (1)-(4) in equation (6), we could calculate the contribution rate under the actuarial equivalence principle and then decide whether it is possible for further reduction and its extent. This paper focuses on the employers' contribution rate, and the actuarial balance rate, $\hat{\theta}$, is

$$
\hat{\theta}=\frac{\sum_{t=t_{0}}^{t_{T}}\left[E_{t} \times \prod_{s=t_{0}}^{t_{T}}\left(1+r_{s}\right)\right]-A S_{t_{0}-1} \times \prod_{t=t_{0}}^{t_{T}}\left(1+r_{t}\right)}{\sum_{t=t_{0}}^{t_{T}}\left[\sum_{i=1}^{4} \sum_{j=1}^{3} \sum_{x=a^{j}}^{b^{j}-1} N_{t, x}^{i, j} \times w_{t} \times \rho_{t} \times \prod_{s=t}^{t_{T}}\left(1+r_{s}\right)\right]}-\sigma .
$$

If $\hat{\theta} \geq \theta$, there is no space for the contribution rate reduction. If $\hat{\theta}<\theta$, the employers' contribution rate can be reduced by $\theta-\widehat{\theta}$.

\section{Parameters Setting}

\subsection{Demographic Parameters.}

(1) Urban population: Based on China's sixth census in 2010 and $1 \%$ mini census in 2015, we rearrange the population data into different cohorts. Firstly, we predict the number of urban and rural births with the estimation of the total fertility rate, fertility pattern, and sex ratio at birth. Secondly, we forecast the number of urban and rural deaths with the assumption of life expectancy and mortality. Lastly, considering the amount of rural-urban migration, we obtain the urban population by age and gender in each future year.

According to China's sixth census (http://www.stats. gov.cn/tjsj/pcsj/rkpc/6rp/indexch.htm), the total fertility rate in 2010 is 1.18 , among which urban and rural are 0.98 and 1.44, respectively. Due to the phenomenon of concealment and omission during the census, existing literature applies different methods to adjust the total fertility rate, which is considered to be 1.4-1.5 (Cai [34]; Chen and Yang [35]). We assume that the total fertility rate is 1.45 and is 1.23 times higher than the original one. The resulted adjusted total fertility rates for urban and rural are 1.205 and 1.771. The two-child policy implemented in 2016 will have a great impact on the fertility rate. A survey conducted by China Women's Federation and Beijing Normal University showed that the proportion of families with one child having an intention to bear a second child was $20.5 \%$. Using the "4-2-1" family microscopic simulation model, we found that the urban total fertility rate is $0.795 \times 1.205+0.205 \times 2=1.368$ and the rural total fertility rate is $0.795 \times 1.771+0.205 \times 2=1.81$. As for other demographic parameters, the fertility pattern is the same with $1 \%$ mini census. The sex ratio to birth is assumed to decrease by 0.3 per year, until 107. Life expectancies are from the "World Population Prospects 2019," mortality rates by age and gender are estimated using Far Eastern life table. The amount of migration from rural to urban follows Jiang [36].
(2) Urban employed population: With the urban population and employment rate from $1 \%$ mini census, assuming that female carders account for $20 \%$ of all female employers, we can calculate the urban employed population by age, gender, and occupation.

(3) The number of UEBPI participants: According to "Statistical Bulletin on the Development of Human Resources and Social Security 2019" (http://www. mohrss.gov.cn/gkml/ghtj/tj/ndtj/202009/t20200911_3 85449.html), the number of UEBPI participants is 434.88 million, among which the number of contributors and retirees is 311.77 million and 123.11 million. To estimate the number of UEBPI participants by age and gender, we assume that the age structure of contributors is consistent with that of urban employees, and the age structure of retirees is consistent with that of the urban elderly. With mortality rates by age and gender, we can estimate the number of the "old people," "older middle-aged people," "younger middle-aged people," and "young people" by age, gender, and occupation.

Figure 2 shows the trends in four kinds of UEBPI participants from 2020 to 2060 . The number of "old people," "older middle-aged people," and "younger middle-aged people" gradually decreases year by year, while the number of "young people" gradually increases year by year. As a result, the number of total UEBPI participants increases first and then decreases to a turning point of 2052 .

\subsection{Policy Parameters.}

(1) Contribution rate, contribution base, and collection rate: At present, China's UEBPI contribution rates of employers and employees are $16 \%$ and $8 \%$, and the legal contribution base is last year's average wage. Driven by interests, most employers desire and require avoidance of paying pension insurance contributions, resulting in the situation where the actual contribution base is much lower than the legal one. Statistics dates show that the actual contribution base accounts for only $65 \%$ of the legal contribution base in recent years. According to the "China Statistical Yearbook" (http://www.stats.gov. $\mathrm{cn} / \mathrm{tjsj} / \mathrm{hdsj} /$ ), the average wage growth rate is approximately equal to the economic growth rate. Considering that China's economic growth rate will 


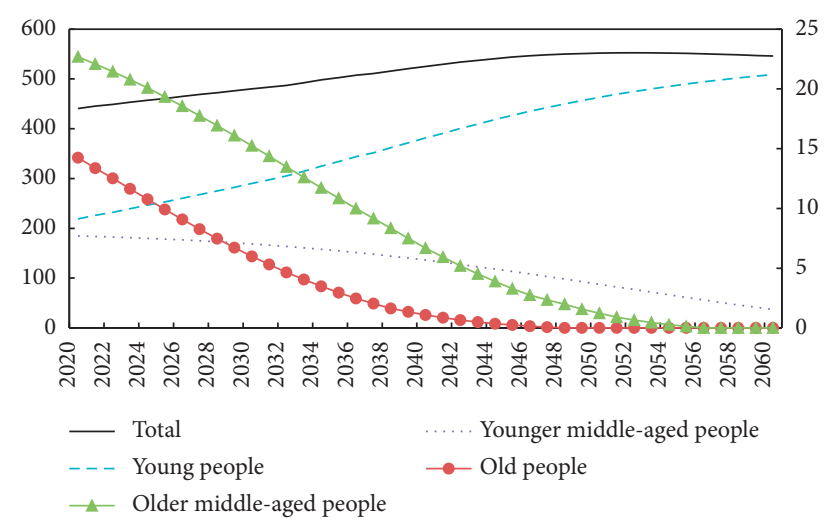

FIgURE 2: Trends in four kinds of UEBPI participants (unit: million).

gradually slow down, we assume that the growth rate of the legal contribution base is $6.5 \%$ in 2020 , which will reduce by 0.5 percentage every five years, till it reaches $2 \%$.

(2) Initial contributory age, retirement age, and the maximum age of survival: According to current employment features and population census in China, we assume that employees enter the labor market at the age of 22, and the maximum age of survival is 100 . That is to say, pension participants' initial contributory age is 22, and they receive pension benefits till 100. According to the current retirement age policy formulated in the early 1950s in China, the age of male is 60 , for female, the age of carder is 55 , and the age of worker is 50 .

(3) Pension payment ratio: The basic pension payment ratios for "old people" and "older middle-aged people" are $70 \%$ and $20 \%$, while the basic pension payment ratios for "younger middle-aged people" and "young people" are related to their contributory years at retirement, $1 \%$ for each contributory year. According to the current retirement age policy, the basic pension payment ratios are $38 \%$ for male, $33 \%$ for female carders, and $28 \%$ for female workers. The number of expected months issuing individual account pension benefits is 139 for male, 170 for female carders, and 195 for female workers. The transitional pension payment ratio for "older middle-aged people" and "younger middle-aged people" is $1.2 \%$.

(4) Growth rate of pension benefits: "The Social Insurance Law of the People's Republic of China" requires setting up a mechanism to adjust pension benefits, and raising pension benefits according to the growth rate of employees' wages and inflation rate. Therefore, we assume that the growth rate of pension benefits is $g=\pi+\alpha \lambda$, where $\pi$ is the inflation rate, $\lambda$ is the growth rate of wage, and $\alpha$ is the economic sharing factor. Based on pension benefits adjustment in practice, we assume that the inflation rate is $2 \%$, and the economic sharing factor is 0.5 .
(5) Return on investment and nominal interest rate of the individual account: China's UEBPI fund is either invested in national debt or reserved in the commercial bank before 2016, resulting in the return on investment to be less than 2\%. Form 2017, the pension fund could be invested in financial markets, but the investment scale is still small. Therefore, we assume the return on investment to be $3 \%$. Based on the regulations of UEBPI, the nominal interest rate of individual account should consider the growth rate of wage and the balance of pension funds and should not be lower than the one-year deposit rate. Based on the nominal interest rate of individual account in recent years, we assume it to be $5 \%$.

\section{Prediction Results}

5.1. Baseline Scenario: No Strategy Intervention. In the baseline scenario, we predict the income, expenditure, current surplus, and accumulated surplus of the UEBPI fund when the contribution rate is $19 \%$ and $16 \%$, respectively, assuming that there is no strategy intervention. The prediction results are summarized in Table 1. The baseline scenario serves as the reference for the analysis of optimization scenarios.

It can be seen from Table 1 that when the contribution rate is $19 \%$, the fund's income increases from 4965.61 billion RMB in 2020 to 22387.59 billion RMB in 2060, with an annual average growth rate of $3.85 \%$. Meanwhile, the fund's expenditure increases from 5295.18 billion RMB in 2020 to 56664.13 billion RMB in 2060, with an annual average growth rate of $6.13 \%$. We can find that with the changes in the income and expenditure, the fund will experience an annual deficit from 2020 and reach 36764.05 billion RMB in 2060. However, according to "Statistical Bulletin on the Development of Human Resources and Social Security 2019," the accumulated surplus of the UEBPI fund was 5462.30 billion RMB in 2019. Based on the return on investment and the annual deficits, it is calculated that the fund will be exhausted in 2025, and the accumulated deficit will be as high as 568681.59 billion RMB in 2060. It means that in the baseline scenario of the contribution rate $19 \%$, the UEBPI fund could last for only 5 years (2020-2024), and the fund will become unsustainable since 2025 . While under the contribution rate of $16 \%$, the reduction of income and the maintenance of expenditure will cause the UEBPI fund to be exhausted in 2024, and the accumulated deficit is 629455.86 billion RMB in 2060 , indicating that the contribution rate reduction will lead to a greater risk of financial imbalance.

Based on the predicted results of the contribution rate $16 \%$, we calculate the actuarial balance rate that could maintain the vertical financial balance from 2020 to 2060 using equation (7), which is $43.34 \%$, a number far beyond $16 \%$. It shows that there is no feasible space for the decrease of pension insurance contribution rate. Therefore, the question is how to maintain the vertical financial balance of the UEBPI fund with contribution rate reduction? In recent years, among all the proposed arrangements related to the improvement of the financial sustainability of the UEBPI 
TABLE 1: Financial balance of the UEBPI fund in baseline scenario (unit: billion RMB).

\begin{tabular}{|c|c|c|c|c|c|c|c|c|}
\hline \multirow{2}{*}{ Year } & \multicolumn{4}{|c|}{$\theta=19 \%$} & \multicolumn{4}{|c|}{$\theta=16 \%$} \\
\hline & $I_{t}$ & $E_{t}$ & $C S_{t}$ & $A S_{t}$ & $I_{t}$ & $E_{t}$ & $C S_{t}$ & $A S_{t}$ \\
\hline 2020 & 4965.61 & 5295.18 & -329.57 & 5296.60 & 4413.87 & 5295.18 & -881.31 & 4744.86 \\
\hline 2021 & 5252.18 & 5821.01 & -568.82 & 4886.67 & 4668.61 & 5821.01 & -1152.40 & 3734.81 \\
\hline 2022 & 5548.84 & 6335.77 & -786.93 & 4246.34 & 4932.30 & 6335.77 & -1403.47 & 2443.38 \\
\hline 2023 & 5856.37 & 6972.37 & -1116.00 & 3257.72 & 5205.66 & 6972.37 & -1766.71 & 749.97 \\
\hline 2024 & 6144.44 & 7746.27 & -1601.82 & 1753.64 & 5461.73 & 7746.27 & -2284.54 & -1512.07 \\
\hline 2025 & 6461.68 & 8484.21 & -2022.54 & -216.29 & 5743.71 & 8484.21 & -2740.50 & -4252.57 \\
\hline 2030 & 8229.43 & 12769.50 & -4540.08 & -17527.33 & 7315.05 & 12769.50 & -5454.46 & -25723.88 \\
\hline 2035 & 10438.51 & 18216.50 & -7777.99 & -50020.81 & 9278.68 & 18216.50 & -8937.82 & -63476.43 \\
\hline 2040 & 13042.81 & 24724.94 & -11682.13 & -100086.68 & 11593.61 & 24724.94 & -13131.33 & -120181.58 \\
\hline 2045 & 16017.97 & 32264.41 & -16246.44 & -171920.97 & 14238.20 & 32264.41 & -18026.22 & -200229.55 \\
\hline 2050 & 18299.96 & 41209.25 & -22909.29 & -272709.16 & 16266.63 & 41209.25 & -24942.62 & -310667.63 \\
\hline 2055 & 20407.20 & 49539.54 & -29132.35 & -406713.52 & 18139.73 & 49539.54 & -31399.81 & -455516.57 \\
\hline 2060 & 22387.59 & 56664.13 & -34276.54 & -568681.59 & 19900.08 & 56664.13 & -36764.05 & -629455.86 \\
\hline
\end{tabular}

fund by the Chinese government, the two-child policy is implemented. However, we still need other risk control strategies, such as implementing the collection system reform, postponing the retirement age, and introducing external finance. Therefore, we analyze the impacts of the said three risk control strategies on alleviating the financial imbalance risk of the UEBPI fund. It should be noted that the following content is analyzed when the contribution rate is $16 \%$.

\subsection{Optimization Scenario 1: Implementing the Collection} System Reform. Pension insurance contributions are collected in three methods, namely, "collected by tax authorities," "collected by social security department," and "collected by tax authorities on behalf of social security department." By 2018, 5, 15, and 17 of 37 contributory districts in China adopted the above three methods, respectively. Collection system reform refers to "collected by tax authorities," which means the tax authorities are responsible for determining the contribution base and collecting the contributions.

Contribution evasion is one of the major issues in pension collection management. According to the "China Enterprise Social Insurance White Paper 2018" (https:// www.51shebao.com/article/detail/2957), only $27 \%$ of the enterprises pay the compliant contributions. It was verified by many studies that "collected by tax authorities" would increase the collection rate (Barrand et al. [37]; Enoff and Mckinnon [38]). Based on China's provincial panel data, Zeng et al. [21] found that the collection rate could be increased by 20.3-25.2 percentage if the contributions were collected by the tax authorities. Gillion [39] pointed out that the collection rate in both eastern and central European countries is $70 \%-80 \%$, and these countries usually adopt the method of "collected by tax authorities." It is assumed that the collection rate will increase to $75 \%$ or $85 \%$ after the collection system reform, namely, the optimization scenario 1 .

It can be seen from Table 2 that, with the increase of the collection rate, the earliest year of the accumulated deficit is delayed. When the collection rate reaches $75 \%$, the earliest year of the accumulated deficit is 2026. However, the number of years with the current deficit is not changed. When the collection rate is as high as $85 \%$, the earliest year of the accumulated deficit is 2029, and the earliest year of the current deficit is 2023. Compared with the baseline scenario, with the collection system reform, the sustainable operation of the fund is extended by 2-5 years, and the amount of accumulated deficit in 2060 is decreased by $11.89 \%-23.84 \%$. However, the fund still shows a large accumulated deficit. To achieve the vertical financial balance, the actuarial balance rate has to be $36.49 \%$ with a collection rate of $75 \%$, or $31.26 \%$ with a collection rate of $85 \%$. In this case, the collection system reform cannot effectively solve the problem associated with financial imbalance risk.

5.3. Optimization Scenario 2: Postponing the Retirement Age. The current retirement age policy in China was adopted at the beginning of the 1950s, when the life expectancy was less than 45 years. However, the life expectancy is more than 77 years in recent years and is expected to continue to grow in the future. The Chinese government proposed to delay the retirement age in 2013 and emphasized several times that the policy would be implemented. However, the detailed scheme has not been announced yet. Raising the retirement age will contribute to the full use of human resources and enhancement of the sustainability of pension funds. Due to its feasibility and effectiveness, the policy of postponing the retirement age is favored by many countries (Borsch-Supana et al. [40]). Table 3 shows the reforms based on the retirement age policy in four representative countries. To deal with the resistance to the implementation of this policy, all of these countries choose to gradually raise the retirement age.

Based on the experiences in developed countries and the situation in China, two schemes are designed for postponing the retirement age. Scheme 1: Raise the retirement age for female workers, female carders, and males from 2022, 2032, and 2042, respectively. The retirement age is delayed by one year every two years, so that the retirement age will rise to 65 in 2051. Scheme 2: Raise the retirement age for female workers, female carders, and males from 2022 at the same time. The retirement age is delayed by one year every two 
TABLE 2: Financial balance of the UEBPI fund in optimization scenario 1.

\begin{tabular}{lccccc}
\hline Scenario & $\begin{array}{c}\text { Collection rate } \\
(\%)\end{array}$ & $\begin{array}{c}\text { Years of the current } \\
\text { deficit }\end{array}$ & $\begin{array}{c}\text { Years of the } \\
\text { accumulated deficit }\end{array}$ & $\begin{array}{c}\text { Accumulated deficit in 2060 } \\
\text { (billion RMB) }\end{array}$ & $\begin{array}{c}\text { Actuarial balance } \\
\text { rate (\%) }\end{array}$ \\
\hline Baseline scenario & 65 & $2020-2060$ & $2024-2060$ & 629455.86 & 43.34 \\
Optimization & 75 & $2020-2060$ & $2026-2060$ & 554624.52 & 36.49 \\
scenario 1 & 85 & $2023-2060$ & $2029-2060$ & 479372.09 & 31.26 \\
\hline
\end{tabular}

TABLE 3: Reforms in the retirement age policy of representative countries.

\begin{tabular}{lccc}
\hline & Before reform & After reform & Detailed scheme \\
\hline U.S. & $\begin{array}{c}\text { Male: } 65 \text { years } \\
\text { Female: } 65 \text { years }\end{array}$ & $\begin{array}{c}\text { Male: } 67 \text { years } \\
\text { Female: } 67 \text { years }\end{array}$ & From 2003, postponing two months each year, till 67 years in 2017 \\
\hline \multirow{2}{*}{ U.K. } & $\begin{array}{c}\text { Male: } 65 \text { years } \\
\text { Female: } 60-65 \text { years }\end{array}$ & $\begin{array}{c}\text { Male: } 68 \text { years } \\
\text { Female: } 68 \text { years }\end{array}$ & $\begin{array}{c}\text { From 2016 to 2018, female increases to 65 years. From 2034 to 2036, both } \\
\text { male and female increase to 67 years, and increase to 68 from 2044 to 2046. }\end{array}$ \\
\hline \multirow{2}{*}{ Germany } & $\begin{array}{c}\text { Male: } 65 \text { years } \\
\text { Female: } 65 \text { years }\end{array}$ & $\begin{array}{c}\text { Male: } 67 \text { years } \\
\text { Female: } 67 \text { years }\end{array}$ & $\begin{array}{c}\text { From 2012, postponing one month each year, till } 66 \text { years in 2023. } \\
\text { Form 2023, postponing two months each year, till 67 years in 2029. }\end{array}$ \\
\hline \multirow{2}{*}{ Australia } & Male: 65 years & Male: 67 years & $\begin{array}{c}\text { From 1995, female postpones six months every 1.5 years, } \\
\text { till 65 years in 2017. From 2018, both and male and female postpone } \\
\text { six months every 1.5 years, till 67 years in 2022. }\end{array}$ \\
\hline
\end{tabular}

years, thereby reaching 65 in 2051, 2041, and 2031 for the above three subgroups of pension participants. Please be noted that we choose 2022 as the first year to implement the policy of postponing the retirement age; this is because the Ministry of Human Resources and Social Security of the People's Republic of China emphasizes that the policy would be implemented in 2022. And we predict the financial sustainability of pension funds in optimization scenario 2 .

It can be seen from Table 4 that postponing the retirement age has an insignificant impact on the number of years for current deficit or accumulated deficit. The main reason is that the policy starts in 2022, and the growth rate of the number of contributors cannot compare with that of the population aging. However, the policy may take effect with time, thereby narrowing the gap between pension fund's income and expenditure, and further resulting in a substantial decrease in the accumulated deficit. Intuitively, postponing the retirement age increases the number of contributors, decreases the number of retirees, extends the contributory years, and reduces the years of receiving benefits. Thus, it leads to more income and less expenditure. If we take a step forward, postponing the retirement age brings impacts to other factors as well. Firstly, it would increase the pension replacement rate, which may result in more expenditure. Secondly, given the growth rate of wage, it would be favorable to raise the wage at the time of retirement, which leads to a higher payment base. Therefore, the impact of postponing the retirement age on the financial sustainability of the UEBPI fund is uncertain. According to Table 4, compared with the baseline scenario, the amount of accumulated deficit in 2060 is decreased by 46.15\% under Scheme 1 and 50.59\% under Scheme 2, and the corresponding actuarial balance rate is reduced by 14.46 and 15.01 percentage, respectively. To sum up, postponing the retirement age would significantly improve the financial sustainability of the UEBPI fund. However, the fund still faces a high risk of financial imbalance, and there is no space for the reduction of the contribution rate.
5.4. Optimization Scenario 3: Introducing External Finance. As one of the major financing sources for the UEBPI fund, the government is responsible for maintaining its financial balance. Although China's UEBPI system does not stipulate the government's contribution responsibility, the government still provides fiscal subsidies to the provinces with an annual deficit in funds. Zheng [3] suggested that fiscal subsidy should be fixed at a certain level, so that the pension system could achieve a balanced development by itself. According to "Statistical Bulletin on the Development of Human Resources and Social Security," the fiscal subsidy accounted for $18 \%-21 \%$ of the UEBPI fund's expenditure from 2015 to 2019, with an average value of $20.17 \%$. Apart from the fiscal subsidy, the transfer of state-owned capital and the use of national social security funds also present key financing sources. To mitigate the impact of population aging on the pension fund, the State Council asked the stateowned enterprises to transfer $10 \%$ of their earnings in terms of shares and profits to fill the funding gap. Based on the data from "Finance Year Book of China," we calculate that the state-owned capital available to be transferred to the UEBPI fund is 104.98 billion RMB in 2018 and 116.07 billion RMB in 2019 , accounting for $2.36 \%$ of the fund's expenditure. The national social security fund is a reserve fund to supplement the pension fund gap during the peak period of population aging. According to the scale of the national social security fund and its investment return, it is supposed to afford at least $1 \%$ of the annual expenditure of the UEBPI fund. Therefore, we assume that the external finance accounts for $23.5 \%$ of the UEBPI fund's expenditure in each future year.

As shown in Table 5, the earliest year of the current deficit and the accumulated deficit is 2023 and 2030, respectively. The amount of accumulated deficit in 2060 is 365175.33 billion RMB, and the actuarial balance rate is $31.14 \%$. Compared with the baseline scenario, with external finance, the time for financial imbalance risk is delayed by 6 years, the accumulated deficit is lowered by 
TABLE 4: Financial balance of the UEBPI fund in optimization scenario 2.

\begin{tabular}{lccccc}
\hline Scenario & $\begin{array}{c}\text { Retirement } \\
\text { age }\end{array}$ & $\begin{array}{c}\text { Years of the current } \\
\text { deficit }\end{array}$ & $\begin{array}{c}\text { Years of the } \\
\text { accumulated deficit }\end{array}$ & $\begin{array}{c}\text { Accumulated deficit in 2060 } \\
\text { (billion RMB) }\end{array}$ & $\begin{array}{c}\text { Actuarial balance } \\
\text { rate (\%) }\end{array}$ \\
\hline Baseline scenario & Current & $2020-2060$ & $2024-2060$ & 629455.86 & 43.34 \\
Optimization & Scheme 1 & $2020-2060$ & $2024-2060$ & 338934.25 & 28.88 \\
scenario 2 & Scheme 2 & $2020-2060$ & $2025-2060$ & 311009.23 & 28.33 \\
\hline
\end{tabular}

TABLE 5: Financial balance of the UEBPI fund in optimization scenario 3.

\begin{tabular}{lccccc}
\hline Scenario & $\begin{array}{c}\text { Percentage of } \\
\text { external finance }\end{array}$ & $\begin{array}{c}\text { Years of the } \\
\text { current deficit }\end{array}$ & $\begin{array}{c}\text { Years of the } \\
\text { accumulated deficit }\end{array}$ & $\begin{array}{c}\text { Accumulated deficit in 2060 Actuarial balance } \\
\text { (billion RMB) }\end{array}$ & $\begin{array}{c}\text { Acte (\%) } \\
\text { rate }\end{array}$ \\
$\begin{array}{l}\text { Baseline scenario } \\
\begin{array}{l}\text { Optimization } \\
\text { scenario 3 }\end{array}\end{array}$ & 0 & $2020-2060$ & $2024-2060$ & 629455.86 & 43.34 \\
\hline
\end{tabular}

$41.99 \%$, and the actuarial balance rate is reduced by 12.20 percentage. It indicates that the introduction of external finance will improve the sustainability of the UEBPI fund. However, the fund is still confronted with a huge financial imbalance risk.

\subsection{Optimization Scenario 4: Combinatorial Optimization.} The results of 1-3 optimization scenarios show that the above three strategies are available to decrease the financial imbalance risk. According to the scale of the accumulated deficit and the actuarial balance rate, the effects of the above three strategies from high to low are postponing the retirement age, introducing external finance, and implementing the collection system reform. However, the accumulated deficit of the UEBPI fund in 2060 is still large. In that case, we combine any two of the above three strategies or all of them, namely, the optimization scenario 4. The forecasting results are shown in Table 6.

It can be seen from Table 6 that, with the combination of any two strategies, the financial sustainability of the UEBPI fund is significantly improved. Besides, the fund could last 7-34 years on a sustainable basis; that is, 3-30 years longer than that in the baseline scenario. In the case with all the three strategies being implemented, the fund can almost maintain its financial sustainability till 2060, its accumulated surplus in 2060 is between -15.80 trillion RMB and 210.42 trillion $\mathrm{RMB}$, and the actuarial balance rate is $12.00 \%-$ $16.36 \%$. To maintain the vertical financial balance from 2020 to 2060 , the contribution rate could be further reduced by $0-4$ percentage. Therefore, it is a prerequisite to implement a package of strategies to control the financial imbalance risk and to provide space for contribution rate reduction.

\section{Sensitivity Analysis}

To examine the robustness of the above conclusions and provide suggestions for China's UEBPI system reform, we further analyze the sensitivity of three parameters, namely, the return on investment of the fund, the growth rate of pension benefits, and the nominal interest rate of the individual account. Results of the sensitivity analysis are summarized in Table 7.

Keeping other parameters constant, if the return on investment increases by one percentage, that is, from $3 \%$ to $4 \%$, the conclusions remain hold. In specific, first, in the baseline scenario with no strategy intervention, the fund could only be sustainably operated until 2023 . Second, by implementing the collection system reform only, if the collection rate increases from $65 \%$ to $75 \%-$ $85 \%$, the fund could last for additional $2-5$ years. Third, by postponing the retirement age only, the fund could only last for an additional $0-1$ year under both the schemes. Fourth, by introducing external finance only, the fund could last for additional 6 years. Fifth, with the combination of any two strategies, the fund could last for additional 3-31 years. Sixth, in the case that the three strategies are implemented at the same time, the fund will almost not have an accumulated deficit before 2060, and the contribution rate is available for a further reduction of $0-4.42$ percentage.

Keeping other parameters constant, if the economic sharing factor in the pension benefits growth formula decreases by 0.25 , that is, from 0.5 to 0.25 , the conclusions remain unchanged. The financial sustainability of the UEBPI fund enhances in each scenario, indicating that a decrease in the growth rate of pension benefits may lead to the decrease of financial imbalance risk. In the case that the all the three strategies are implemented, the actuarial balance rate is $9.80 \%-13.46 \%$, which means the contribution rate could be further reduced by $2.54-6.20$ percentage.

Keeping other parameters constant, if the nominal interest rate of the individual account decreases by one percentage, that is, from $5 \%$ to $4 \%$, the conclusions are also right. The results also show that the reduction of the nominal interest rate could decrease the financial imbalance risk. More importantly, if the three strategies are implemented together, the actuarial balance 
TABLE 6: Financial balance of the UEBPI fund in optimization scenario 4 .

\begin{tabular}{|c|c|c|c|c|c|}
\hline $\begin{array}{l}\text { Collection rate } \\
(\%)\end{array}$ & $\begin{array}{c}\text { Postponing retirement } \\
\text { age scheme }\end{array}$ & $\begin{array}{l}\text { Percentage of } \\
\text { external finance }\end{array}$ & $\begin{array}{c}\text { Years of the } \\
\text { accumulated deficit }\end{array}$ & $\begin{array}{c}\text { Accumulated deficit in } 2060 \\
\text { (billion RMB) }\end{array}$ & $\begin{array}{c}\text { Actuarial balance } \\
\text { rate }(\%)\end{array}$ \\
\hline 65 & $\mathrm{~N} / \mathrm{A}$ & 0 & $2024-2060$ & 629455.86 & 43.34 \\
\hline 75 & Scheme 1 & 0 & $2027-2060$ & 249290.03 & 23.97 \\
\hline 85 & Scheme 1 & 0 & $2031-2060$ & 158865.11 & 20.21 \\
\hline 75 & Scheme 2 & 0 & $2035-2060$ & 214709.35 & 21.75 \\
\hline 85 & Scheme 2 & 0 & $2053-2060$ & 109071.36 & 18.25 \\
\hline 75 & $\mathrm{~N} / \mathrm{A}$ & $23.5 \%$ & $2035-2060$ & 288430.07 & 25.92 \\
\hline 85 & N/A & $23.5 \%$ & $2042-2060$ & 208173.54 & 21.93 \\
\hline 65 & Scheme 1 & $23.5 \%$ & $2032-2060$ & 119880.02 & 20.10 \\
\hline 65 & Scheme 2 & $23.5 \%$ & $2054-2060$ & 80229.67 & 18.15 \\
\hline 75 & Scheme 1 & $23.5 \%$ & $2059-2060$ & 15798.01 & 16.36 \\
\hline 85 & Scheme 1 & $23.5 \%$ & N/A & -127517.14 & 13.49 \\
\hline 75 & Scheme 2 & $23.5 \%$ & $\mathrm{~N} / \mathrm{A}$ & -61898.57 & 14.67 \\
\hline 85 & Scheme 2 & $23.5 \%$ & N/A & -210417.53 & 12.00 \\
\hline
\end{tabular}

TABLE 7: Results of the sensitivity analysis of three parameters.

\begin{tabular}{|c|c|c|c|c|c|c|c|c|}
\hline \multirow[b]{2}{*}{$\begin{array}{l}\text { Collection } \\
\text { rate }(\%)\end{array}$} & \multirow{2}{*}{$\begin{array}{l}\text { Postponing } \\
\text { retirement age } \\
\text { scheme }\end{array}$} & \multirow{2}{*}{$\begin{array}{c}\text { Percentage of } \\
\text { external } \\
\text { finance }\end{array}$} & \multicolumn{2}{|c|}{ Return on investment } & \multicolumn{2}{|c|}{$\begin{array}{l}\text { Growth rate of pension } \\
\text { benefits }\end{array}$} & \multicolumn{2}{|c|}{ Nominal interest rate } \\
\hline & & & $\begin{array}{c}\text { Years of the } \\
\text { accumulated } \\
\text { deficit }\end{array}$ & $\begin{array}{c}\text { Actuarial } \\
\text { balance rate } \\
(\%)\end{array}$ & $\begin{array}{c}\text { Years of the } \\
\text { accumulated } \\
\text { deficit }\end{array}$ & $\begin{array}{c}\text { Actuarial } \\
\text { balance rate } \\
(\%)\end{array}$ & $\begin{array}{c}\text { Years of the } \\
\text { accumulated } \\
\text { deficit }\end{array}$ & $\begin{array}{c}\text { Actuarial } \\
\text { balance rate } \\
(\%)\end{array}$ \\
\hline 65 & $\mathrm{~N} / \mathrm{A}$ & 0 & $2024-2060$ & 41.96 & $2024-2060$ & 37.47 & $2024-2060$ & 42.19 \\
\hline 75 & N/A & 0 & $2026-2060$ & 35.30 & $2027-2060$ & 31.41 & $2026-2060$ & 35.50 \\
\hline 85 & N/A & 0 & $2029-2060$ & 30.21 & $2031-2060$ & 26.77 & $2029-2060$ & 30.38 \\
\hline 65 & Scheme 1 & 0 & $2024-2060$ & 28.47 & $2025-2060$ & 24.51 & $2024-2060$ & 28.17 \\
\hline 65 & Scheme 2 & 0 & $2025-2060$ & 25.64 & $2027-2060$ & 22.57 & $2025-2060$ & 25.67 \\
\hline 65 & N/A & $23.5 \%$ & $2030-2060$ & 30.06 & $2032-2060$ & 26.66 & $2030-2060$ & 30.26 \\
\hline 75 & Scheme 1 & 0 & $2027-2060$ & 23.61 & $2029-2060$ & 20.18 & $2027-2060$ & 23.34 \\
\hline 85 & Scheme 1 & 0 & $2032-2060$ & 19.89 & 2039-2060 & 16.87 & $2032-2060$ & 19.66 \\
\hline 75 & Scheme 2 & 0 & $2035-2060$ & 21.16 & $2053-2060$ & 18.50 & $2035-2060$ & 21.18 \\
\hline 85 & Scheme 2 & 0 & $2054-2060$ & 17.73 & N/A & 15.38 & $2055-2060$ & 17.75 \\
\hline 75 & N/A & $23.5 \%$ & $2035-2060$ & 24.99 & $2040-2060$ & 22.03 & $2035-2060$ & 25.16 \\
\hline 85 & N/A & $23.5 \%$ & $2043-2060$ & 21.11 & $2051-2060$ & 18.50 & $2042-2060$ & 21.26 \\
\hline 65 & Scheme 1 & $23.5 \%$ & $2033-2060$ & 19.76 & $2057-2060$ & 16.76 & $2033-2060$ & 19.56 \\
\hline 65 & Scheme 2 & $23.5 \%$ & $2055-2060$ & 17.60 & N/A & 15.28 & $2055-2060$ & 17.65 \\
\hline 75 & Scheme 1 & $23.5 \%$ & 2060 & 16.06 & N/A & 13.46 & N/A & 15.88 \\
\hline 85 & Scheme 1 & $23.5 \%$ & N/A & 13.23 & N/A & 10.94 & N/A & 13.07 \\
\hline 75 & Scheme 2 & $23.5 \%$ & N/A & 14.19 & $\mathrm{~N} / \mathrm{A}$ & 12.17 & N/A & 14.23 \\
\hline 85 & Scheme 2 & $23.5 \%$ & N/A & 11.58 & N/A & 9.80 & N/A & 11.61 \\
\hline
\end{tabular}

rate will be $11.61 \%-15.88 \%$, indicating that the contribution rate could be further reduced by $0.12-4.39$ percentage.

\section{Concluding Remarks}

Combined with the regulation and reform tendency of China's UEBPI, we construct an actuarial model to analyze the financial imbalance risk of contribution rate reduction in several scenarios and examine the feasible ways to further reduce the contribution rate. The main findings are as follows. First, in the baseline scenario with no strategy intervention, the UEBPI fund will have accumulated deficits since 2024 and the actuarial balance rate is $43.34 \%$ between 2020 and 2060. It indicates that the fund is confronted with a high risk of financial imbalance, and there is no space for further reduction of the rate. Second, in the scenarios with single strategy implemented (the collection system reform, delay of retirement age, or the introduction of external finance), the financial sustainability of the UEBPI fund could be improved to some extent. However, the financial imbalance risk remains huge, and therefore limits the space for contribution rate reduction. Third, in the scenario with the combination of any two said strategies, the fund could be operated on a sustainable basis until 2027 at least, but the actuarial balance rate is still greater than $16 \%$. In the case that all the three strategies are implemented, the fund will almost not have an accumulated deficit before 2060, and the contribution rate can be further reduced by $0-4$ percentage. Fourth, whether we choose to increase the return on investment or decrease the growth rate of pension benefits and the nominal interest rate, these strategies will help to alleviate the financial imbalance risk of the UEBPI fund.

Based on the above conclusions, we put forward several policy recommendations for the control of the financial 
imbalance risk of the UEBPI fund. The first is to implement the collection system reform quickly. If the information system of tax authorities is applied to pension insurance contribution collection, it would be possible to avoid contribution evasion, and to increase the collection rate. The second is to carry out the postponing retirement age policy as soon as possible. The retirement age should gradually be raised and should be set differently based on the employees' sex and occupation. It is also plausible to provide a buffer period, so that individuals could be adapted to this policy. The third is to broaden financing sources for the pension system. On the one hand, it is necessary to clarify the specific responsibility of the government in the pension system and determine the scale of fiscal subsidies as a certain percentage of the fund's expenditure. On the other hand, it is advisable to speed up the process of transferring state-owned capital to pension funds and continue to enrich the fund's income. Fourthly, some possible strategies also included strengthening the investment management capabilities of pension funds, relaxing restrictions on the investment scope and ratio, establishing a reasonable pension benefits adjustment mechanism, and lowering the nominal interest rate of the individual account.

\section{Data Availability}

All the data are available from National Bureau of Statistics at http://www.stats.gov.cn/tijsj/ndsj/ and the Statistical Bulletin on the Development of Human Resources and Social Security at http://www.mohrss.gov.cn/gkml/ghtj/tj/ ndtj/.

\section{Conflicts of Interest}

The authors declare that they have no conflicts of interest.

\section{Acknowledgments}

This study was supported by the National Natural Science Foundation of China (72004183) and the Fundamental Research Funds for the Central Universities (JBK2103001).

\section{References}

[1] X. Liu, Y. Zhang, L. Fang, Y. Li, and W. Pan, "Reforming China's pension scheme for urban workers: liquidity gap and policies' effects forecasting," Sustainability, vol. 7, pp. 10876-10894, 2015.

[2] Z. Q. Luo, Z. Y. Chen, and A. Lu, "A study on the effects of population factors on the payment balance of basic pension insurance funds in China," Forecasting, vol. 29, no. 2, pp. 42-46, 2010.

[3] Y. Xie, X. Zhang, H. Lv, and X. Guo, "The new fertility policy and the actuarial balance of China urban employee basic endowment insurance fund based on stochastic mortality model," Mathematical Problems in Engineering, vol. 2020, Article ID 3596384, 12 pages, 2020.

[4] Y. Zeng and B. Yu, "Tackling China's pension fund payment crisis: will the 'Two-Child Policy' be the answer? An example with the basic pension insurance program for urban employees," China Economist, vol. 5, no. 1, pp. 20-36, 2015.
[5] World Bank, Averting the Old-Age Crisis: Policies to Protect the Old and Promote Growth, The World Bank, Washington, DC, USA, 1994.

[6] R. Holzmann and R. Hinz, Old-Age Income Support in the 21st Century: An International Perspective on Pension Systems and Reform, The World Bank, Washington, DC, USA, 2005.

[7] D. Blake and L. Mayhew, "On the sustainability of the UK state pension system in the light of population ageing and declining fertility," The Economic Journal, vol. 116, no. 6, pp. 286-305, 2006.

[8] J. D. Rauh and R. Novymarx, "Policy options for state pension systems and their impact on plan liabilities," Journal of Pension Economics and Finance, vol. 10, no. 2, pp. 173-194, 2011.

[9] A. Billig and J. C. Ménard, "Actuarial balance sheets as a tool to assess the sustainability of social security pension systems," International Social Security Review, vol. 66, no. 2, pp. 31-52, 2013.

[10] C. Metzger, "An actuarial balance sheet of the Swiss old-age pension scheme," International Social Security Review, vol. 71, no. 1, pp. 25-49, 2018.

[11] J. Bongaarts, "Population aging and the rising cost of public pensions," Population and Development Review, vol. 30, no. 1, pp. 1-23, 2004.

[12] Y. Sin, China Pension Liabilities and Reform Options for Old Age Insurance, World Bank Working Paper, vol. 2005-1, 2005.

[13] A. A. Belolipetskii and M. A. Lepskaya, "A mathematical model of pension fund operation and methods of fund stability analysis," Computational Mathematics and Modeling, vol. 29, no. 2, pp. 233-243, 2018.

[14] W. L. Heeringa and A. L. Bovenberg, "Generational impacts of demographic changes in Pay-as-you-go pension schemes: measurement and application to The Netherlands," De Economist, vol. 160, no. 1, pp. 1-16, 2012.

[15] T. Liu and L. Sun, "Pension reform in China," Journal of Aging Society Policy, vol. 28, no. 1, pp. 15-28, 2016.

[16] P. Whiteford and E. Whitehouse, "Pension challenges and pension reforms in OECD countries," Oxford Review of Economic Policy, vol. 22, no. 1, pp. 78-94, 2006.

[17] B. Lin, "Impact of population ageing on China's old-age insurance system for urban employees," Chinese Journal of Population Science, vol. 24, no. 1, pp. 84-92, 2010, in Chinese.

[18] P. Jing and Q. Hu, "The Potential cutting extent for social pooling contribution rate of state basic pension scheme for enterprise employees," Chinese Journal of Population Science, vol. 31, no. 1, pp. 21-33, 2017, in Chinese.

[19] Y. Zeng, N. Liu, and J. Gao, "The decreasing space of China's basic pension insurance for urban employees and the effect on public expenditures," Journal of Finance and Economics, vol. 44, no. 12, pp. 70-84, 2018, in Chinese.

[20] Y. Guo and Y. Zhang, "Can stringent contribution collection reduce contribution rate of basic social pension insurance for urban employees?" Insurance Studies, vol. 26, no. 2, pp. 101113, 2019, in Chinese.

[21] Y. Zeng, S. Li, and X. Li, "Research on the influence of tax authority's full responsibility of collecting social security fee on the space of reducing the contribution rate of pension insurance," Public Finance Research, vol. 41, no. 2, pp. 96-112, 2020, in Chinese.

[22] A. Kugler and M. Kugler, "Labor market effects of payroll taxes in developing countries: evidence from Colombia," Economic Development and Cultural Change, vol. 57, no. 2, pp. 335-358, 2009. 
[23] I. Iturbe-Ormaetxe, "Salience of social security contributions and employment," International Tax and Public Finance, vol. 22, no. 5, pp. 1-19, 2015.

[24] S. Ma, X. Meng, and L. Gan, "Effect to pension on employment and firm average wage," China Economic Quarterly, vol. 3, no. 3, pp. 969-1000, 2014, in Chinese.

[25] N. Chaudhry, H. Yong, and V. Chris, "How does the funding status of defined benefit pension plans affect investment decisions of firms in the United States?" Journal of Business Finance and Accounting, vol. 141, no. 23, pp. 4513-4525, 2016.

[26] E. Saez, B. Schoefer, and D. Seim, "Payroll taxes, firm behavior, and rent sharing: evidence from a young workers' tax cut in Sweden," American Economic Review, vol. 109, no. 5, pp. 1717-1763, 2019.

[27] J. Tang and J. Feng, "Do social security contributions affect the capital-labor ratio: evidence from China," Economic Research Journal, vol. 65, no. 11, pp. 87-101, 2019.

[28] I. Ehrlich and J. Kim, "Social security and demographic trends: theory and evidence from the international experience," Review of Economic Dynamics, vol. 10, no. 1, pp. 55-77, 2007.

[29] S. L. Yew and J. Zhang, "Optimal social security in a dynastic model with human capital externalities, fertility and endogenous growth," Journal of Public Economics, vol. 93, no. 3, pp. 605-619, 2009.

[30] L. Fanti and L. Gori, "Economic growth and stability with public Pay-as-you-go pensions and private intra-family oldage insurance," Research in Economics, vol. 66, no. 3, pp. 219-229, 2012.

[31] H. Peng, H. Qiu, C. Zhu, and A. Li, "Pension contribution rate, public educational investment and pension replacement rate," The Journal of World Economy, vol. 41, no. 12, pp. 148-168, 2018.

[32] X. Yi, R. Guo, and Y. Qi, "Stabilization of chaotic systems with both uncertainty and disturbance by the UDE-based control method," IEEE Access, vol. 8, no. 1, pp. 62471-62477, 2020.

[33] L. Liu, B. Li, and R. Guo, "Consensus control for networked manipulators with switched parameters and topologies," IEEE Access, vol. 9, no. 1, pp. 9209-9217, 2021.

[34] Y. Cai, "China's new demographic reality: learning from the 2010 census," Population and Development Review, vol. 39, no. 3, pp. 371-396, 2013.

[35] W. Chen and S. Yang, "China's fertility in 2010: an indirect estimation using brass P/F ratio method," Population Research, vol. 38, no. 6, pp. 16-24, 2014, in Chinese.

[36] Y. Jiang, "Study on the intergenerational balance of China's pension system for urban employees," World Economic Papers, vol. 27, no. 1, pp. 58-69, 2009, in Chinese.

[37] P. Barrand, S. G. Ross, and G. Harrison, "Integrating a unified revenue administration for tax and social contribution collections: experiences of Central and Eastern European countries," IMF Working Papers, WP/04/237, 2004.

[38] L. D. Enoff and R. Mckinnon, "Social security contribution collection and compliance: improving governance to extend social protection," International Social Security Review, vol. 64, no. 4, pp. 99-119, 2011.

[39] C. Gillion, Social Security Pensions: Development and Reforms, International Labor Organization, Geneva, Switzerland, 2000.

[40] A. Börsch-Supana, K. Härtla, and A. Ludwiga, "Aging in Europe: reforms, international diversification and behavioral reactions," American Economic Review, vol. 104, no. 5, pp. 224-229, 2014. 